\title{
The effectiveness of Payments for Ecosystem Services at delivering improvements in water quality: lessons for experiments at the landscape scale
}

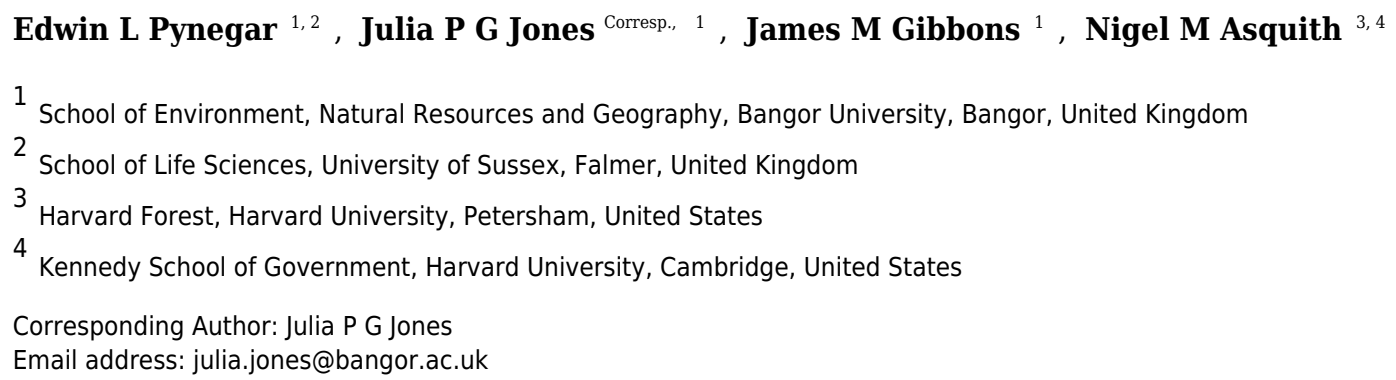

Background. Randomised Control Trials (RCTs) are used in impact evaluation in a range of fields. However, despite calls for their greater use in environmental management, their use to evaluate landscape scale interventions remains rare. Payments for Ecosystem Services (PES) incentivise land users to manage land to provide environmental benefits. We present the first RCT evaluation of a PES program aiming to improve water quality. Watershared is a PES program which incentivises landowners to avoid deforestation and exclude cattle from riparian forests. Using this unusual landscape-scale experiment we explore the efficacy of Watershared at improving water quality, and draw lessons for future RCT evaluations of landscape-scale environmental management interventions. Methods. One hundred and twenty-nine communities in the Bolivian Andes were randomly allocated to treatment (offered Watershared agreements) or control (not offered agreements) following baseline data collection (including Escherichia coli contamination in most communities) in 2010. We collected end-line data in 2015. Using our end-line data, we explored the extent to which variables associated with the intervention (e.g. cattle exclusion, absence of faeces) predict water quality locally. We then investigated the efficacy of the intervention at improving water quality at the landscape scale using the RCT. This analysis was done in two ways; for the subset of communities for which we have both baseline and end-line data from identical locations we used difference-in-differences (matching on baseline water quality), for all sites we compared control and treatment at end-line controlling for selected predictors of water quality. Results. The presence of cattle faeces in water adversely affected water quality suggesting excluding cattle has a positive impact on water quality locally. However, both the matched difference-indifferences analysis and the comparison between treatment and control communities at end-line suggested Watershared was not effective at reducing $E$. coli contamination at the 
landscape scale. Uptake of Watershared agreements was very low and the most important land from a water quality perspective (land around water intakes) was seldom enrolled. Discussion. Although excluding cattle may have a positive local impact on water quality, higher uptake and better targeting would be required to achieve a significant impact on the quality of water consumed in the communities. Although RCTs potentially have an important role to play in building the evidence base for approaches such as PES, they are far from straightforward to implement. In this case, the randomised trial was not central to concluding that Watershared had not produced a landscape scale impact. We suggest that this RCT provides valuable lessons for future use of randomised experiments to evaluate landscape-scale environmental management interventions. 
1 The effectiveness of Payments for Ecosystem Services at delivering improvements in water 2 quality: lessons for experiments at the landscape scale

3

4 Author Names and Affiliations

5 Edwin L. Pynegar ${ }^{a}$, b, Julia P. G. Jones ${ }^{a}$, James M. Gibbons ${ }^{a}$, and Nigel M. Asquith ${ }^{c, d}$

6 a School of Environment, Natural Resources and Geography, Bangor University, Bangor, UK.

7 b School of Life Sciences, University of Sussex, Falmer, UK.

$8 \quad$ c Harvard Forest, Harvard University, Petersham, USA.

9 d Harvard Kennedy School, Harvard University, Cambridge, USA.

10 Corresponding author

11 Julia P G Jones, julia.jones@bangor.ac.uk 


\section{Abstract}

Background. Randomised Control Trials (RCTs) are used in impact evaluation in a range of fields. However, despite calls for their greater use in environmental management, their use to evaluate landscape scale interventions remains rare. Payments for Ecosystem Services (PES) incentivise land users to manage land to provide environmental benefits. We present the first RCT evaluation of a PES programme aiming to improve water quality. Watershared is a PES programme which incentivises landowners to avoid deforestation and exclude cattle from riparian forests. Using this unusual landscape-scale experiment we explore the efficacy of Watershared at improving water quality, and draw lessons for future RCT evaluations of landscape-scale environmental management interventions.

Methods. One hundred and twenty-nine communities in the Bolivian Andes were randomly allocated to treatment (offered Watershared agreements) or control (not offered agreements) following baseline data collection (including Escherichia coli contamination in most communities) in 2010. We collected end-line data in 2015. Using our end-line data, we explored the extent to which variables associated with the intervention (e.g. cattle exclusion, absence of faeces) predict water quality locally. We then investigated the efficacy of the intervention at improving water quality at the landscape scale using the RCT. This analysis was done in two ways; for the subset of communities for which we have both baseline and end-line data from identical locations we used difference-in-differences (matching on baseline water quality), for all sites we compared control and treatment at end-line controlling for selected predictors of water quality.

Results. The presence of cattle faeces in water adversely affected water quality suggesting excluding cattle has a positive impact on water quality locally. However, both the matched difference-in-differences analysis and the comparison between treatment and control communities at end-line suggested Watershared was not effective at reducing E. coli contamination at the landscape scale. Uptake of Watershared agreements was very low and the most important land from a water quality perspective (land around water intakes) was seldom enrolled.

Discussion. Although excluding cattle may have a positive local impact on water quality, higher uptake and better targeting would be required to achieve a significant impact on the quality of water consumed in the communities. Although RCTs potentially have an important role to play in building the evidence base for approaches such as PES, they are far from straightforward to 
42 implement. In this case, the randomised trial was not central to concluding that Watershared had 43 not produced a landscape scale impact. Nevertheless we suggest that this RCT provides valuable

lessons for future use of randomised experiments to evaluate landscape-scale environmental management interventions.

\section{Introduction}

Whether an intervention is effective at delivering the outcomes expected is a key question for evidence-based policy making (e.g. White, 2013). This question is highly pertinent in the field of conservation and environmental management as awareness grows of the amount of money that has been spent on interventions with limited understanding of their effectiveness (Ferraro \& Pattanayak, 2006; Bowler et al., 2012; Waeber et al., 2016; Salzman et al., 2018). As a result, conservation effectiveness is being widely discussed in the academic literature (Baylis et al., 2016; Börner et al., 2016; Sutherland \& Wordley, 2017), the policy literature (Puri et al., 2016; Duchelle, Wunder \& Martius, 2018), conservation journalism (Dasgupta, Gaworecki \& Burivalova, 2018) and the mainstream media (Mooney, 2016). Randomised Control Trials (RCTs), in which experimental units are randomly allocated to treatment or control groups, allow the creation of robust counterfactuals from which to infer what would have happened in the absence of the intervention (e.g. Rubin 1974). RCTs are widely used in many areas of public policy including medicine, education, and development economics (Glennerster \& Takavarasha, 2013; Council of Economic Advisers, 2014). Although small-scale RCTs have been a mainstay of applied ecological experiments for decades, there are very few examples of RCTs of large-scale environmental management interventions, and there have been calls for their increased use (Greenstone \& Gayer, 2009; Samii et al., 2014; Baylis et al., 2016; Börner et al., 2016, 2017).

Payments for Ecosystem Services (or Payments for Environmental Services - the terms are largely interchangeable [Wunder, 2015]) translate external, non-market values of the environment into financial incentives for local actors to provide environmental services. The focus of many PES programs in Latin America (Martin-Ortega, Ojea \& Roux, 2013; Grima et al., 2016), and to a lesser extent in Asia and Africa, e.g. (Calvet-Mir et al., 2015) is the increase or maintenance of supply of good quality water. At least 1.8 billion people still rely on drinking water sources contaminated with faecal matter (Bain et al., 2014a). Where sources lack adequate physical or chemical treatment the quality of drinking water is influenced by land use and ecosystem management around and 
upstream of those water sources. Hence provision of clean water can be considered as an ecosystem service or as a precursor to multiple ecosystem services benefiting society (Keeler et al., 2012). Despite the increasing number of PES programs in operation, there are very few robust evaluations of the extent to which they deliver the outcomes they seek to supply (Pattanayak, Wunder \& Ferraro, 2010; Miteva, Pattanayak \& Ferraro, 2012; Naeem et al., 2015; Baylis et al., 2016; Börner et al., 2017; Ferraro, 2017; Salzman et al., 2018). We know of only a single published Randomised Control Trial of a PES (evaluating the impact of a program in Uganda on deforestation; Jayachandran et al., 2017) and none evaluating the impact of PES on water quality.

Gastrointestinal illnesses caused by consumption of contaminated water are a major cause of mortality and morbidity in the developing world (Prüss-Ustün et al., 2014). Escherichia coli is a bacterium that lives only in the guts of warm-blooded animals (Leclerc et al., 2001). While some strains of $E$. coli are pathogenic, the majority are not but are useful indicators of faecal contamination and the presence of other pathogens (Ashbolt, Grabow \& Snozzi, 2001). Sources of faecal contamination may include faulty sewerage systems and leaking septic tanks (Richards et al., 2016), open defecation (Spears, Ghosh \& Cumming, 2013), or the presence of wildlife (Ahmed et al., 2012). However, a major source of contamination is the presence of domestic livestock, particularly free-roaming cattle (Crane et al., 1983). Therefore, cattle exclusion has been practiced as a means of reducing faecal contamination of watercourses. In the UK, for example, the Good Agricultural and Environmental Conditions standard 1 requires farmers in receipt of certain subsidies to maintain buffer strips and refrain from spreading manure within areas close to water bodies (Anonymous, 2016). There is evidence of such actions being effective at significantly reducing E. coli concentration and other faecal contamination of water supplies (Sunohara et al., 2012). However, many uncertainties remain about the extent to which these interventions, incentivised via a PES program, can deliver consistent benefits in water quality at the landscape scale.

The Bolivian non-governmental organization Fundación Natura Bolivia (Natura) began using inkind incentives to encourage conservation in the Andean region of Bolivia in 2003. Their program, now known as Watershared, aims to slow forest loss and protect the quality of water available to communities through providing modest development support in exchange for avoiding deforestation and excluding livestock from riparian forest (Bottazzi et al., 2018). Although Natura 
102 does not characterise Watershared as PES (Asquith, 2016), the program meets the most widely 103 used PES definition (Wunder, 2015): "voluntary transactions between service users and service 104 providers that are conditional on agreed rules of natural resource management for generating 105 offsite services". As of 2016, 210,000 hectares of forest owned by 4,500 households were under 106 Watershared conservation agreements (Asquith, 2016).

107 Given the growing interest in evaluating the effectiveness of different conservation approaches, 108 Natura established a Randomised Control Trial (RCT) to evaluate Watershared. One hundred and 109 twenty-nine communities were randomly allocated to control (not offered Watershared 110 agreements) or treatment groups (offered agreements). We use this unique setup to investigate the 111 effectiveness of the intervention at delivering improvements in microbial water quality. We 112 address three interconnected questions: 1) Do the features of Watershared agreements (e.g. cattle 113 exclusion, absence of faeces) have a measurable impact on water quality at a site, accounting for 114 other predictors? 2) Did the implementation of Watershared in treatment communities result in an 115 improvement in water quality relative to control communities? 3) What lessons does the 116 Watershared RCT evaluation offer for the wider use of experiments to evaluate the impact of 117 conservation interventions at the landscape scale? 


\section{Materials and Methods}

\section{Context and RCT design}

120 This article focuses on the Watershared intervention in the Río Grande Valles Cruceños Natural 121 Integrated Management Area (Spanish acronym ANMI Río Grande-Valles Cruceños), a protected area 122 of $7339 \mathrm{~km}^{2}$ in the Andean region of the Santa Cruz Department in eastern Bolivia (Fig. 1). Forests 123 in this area are perceived locally as contributing to providing high-quality water for human 124 consumption and irrigation, despite the mixed scientific evidence on this topic (Bruijnzeel, 2004; 125 Ponette-González et al., 2015). Gastrointestinal illnesses are endemic; for example, in 2015 the 126 health centre of Moro Moro, a community of approximately 800 people, treated 236 cases of 127 diarrhoea (information from Servicio Nacional Integral de Salud, Centro de Salud Moro Moro, 128 obtained $4^{\text {th }}$ April 2016). Faecal contamination from cattle is widely considered an important contributor to the high prevalence of these diseases as the traditional farming system involves cattle grazing freely within the forests from where most communities take their water. While some communities have rudimentary sedimentation and filtration systems, these are of limited effectiveness and often become clogged with sediment after each rainfall event. Chlorination or other chemical treatment is rare.

In 2010, 129 communities within the Río Grande-Valles Cruceños protected area were selected for inclusion in a Randomised Control Trial (Fig. 1). Consent to randomization was granted by community leaders on the understanding that the intervention would subsequently be implemented in all communities (this general roll-out was conducted in 2016). Communities were randomly allocated to control (64 of these communities in which conservation agreements were not offered) or treatment (65 communities in which agreements were offered) groups following stratification based on municipality, community size, and estimated cattle density. The RCT was not blinded as participants unavoidably knew whether they belonged to a treatment or control community. However, in order to avoid observer bias effects during data collection, those conducting water quality monitoring did not know which communities belonged to the treatment or control group.

Individuals belonging to treatment communities were offered the chance to conserve land belonging to them under Watershared agreements (see Bottazzi et al., [2018] for more detail on the Watershared program) and received education on the importance of cattle exclusion and forest conservation for the maintenance of water quality and quantity. Individuals belonging to control 
148 communities received the environmental education only. Natura offered landowners in treatment

149 communities three-year conservation agreements to conserve upstream forest and exclude cattle 150 from riparian forest in return for in-kind incentives such as fruit trees, barbed wire, or irrigation

151 materials. Participants could enrol their land in one of three kinds of agreements (for details see

152 Table S1). In this paper we only consider level 1 agreements, in which landowners were offered $153 \$ 10 /$ hectare/year in-kind equivalent (plus the equivalent of $\$ 100$ regardless of the size of the area 154 enrolled) in return for conserving forested land within $100 \mathrm{~m}$ of a watercourse and excluding cattle 155 from these areas. Landowners were offered the opportunity to enrol their land twice per year, 156 beginning in August 2011. Compliance monitoring and distribution of the in-kind compensations 157 was conducted yearly. A recent analysis suggests that $31 \%$ of the area of level 1 agreements 158 resulted in additional conservation (i.e. cattle were kept out of land which otherwise they would 159 have been allowed in; Bottazzi et al., 2018).

\section{Sampling strategy}

161 Our analyses are based upon two rounds of monitoring of the quality of water intended for human consumption. A baseline was taken between February and July of 2010 by the NGO Natura before the sites were allocated to control or treatment groups. The allocation to control or treatment was not stratified by measured water quality at the sites, and the baseline data was not otherwise used until our team started work on the project in 2013. A more detailed end-line monitoring round was undertaken by our team from Bangor University in collaboration with Natura between March and May of 2015, i.e. following completion of the first signed agreements. In the end-line we had more stringent protocols and also measured a number of additional potential indicators of water quality.

The communities within the RCT are small (maximum number of households is 123; Bottazzi et al., 2017) with diverse water supply systems. Some have a single water intake, others multiple intakes and in a few cases no functional intake at all (community members take water directly from streams or other water bodies). Resource and logistical constraints meant that not all intakes and taps could be sampled and so the tap supplying the community's school, along with the intake supplying that tap, were taken as sampling sites based on the assumption that these would have the greatest importance for health (Fig. 2). In cases where the community had no school, we monitored at the intake which supplied the greatest number of households and a representative tap

177 fed by that intake. In the cases in which the community had no functional water system at all, we 
178 took a sample in the water body where the greatest number of households collected their water.

179 Thus most communities had two site measurements (intake and tap), whereas a few (those lacking 180 an intake) only had one, in a few communities two intakes were measured. In this paper we refer 181 to the combination of an intake and a tap (or the location where households collected water where 182 an intake is not present) as a water system.

183 In 2010 the randomisation process assigned 129 communities to control or treatment group. 184 Independently technicians from Natura monitored water quality in 120 of these communities. In 185 the 2015 end-line we monitored 118 communities that were part of the RCT plus an additional six 186 communities not in the RCT. Two of the RCT sites were excluded from the end-line analysis as 187 their water system was supplied from rainfall collected from roofs and therefore cattle could not 188 affect water quality. Water quality was measured at each site (see below). In 2015 we also recorded 189 other characteristics of the site which may predict water quality. Table S2 summarises the sample 190 size for each analysis.

191 The Natura technicians who took water measurements in 2010 recorded the location with a 192 handheld GPS. However when we returned in 2015 it was not always possible to confirm that we 193 were at the same water intake (GPS readings in forest can be inaccurate). In addition, between 194 baseline data collection in 2010 and our team's visit in 2015, the location of both water intakes 195 and the main tap serving the community had changed in a number of sites. As a result, for only 83 196 sites in 47 communities were we 100\% confident that had measured water quality at the same 197 location between 2010 and 2015 (Table S2). The fact that end-line data from the same location 198 was not available from all sites is somewhat analogous to the common problem of attrition due to 199 loss to follow up in clinical trials (Jüni, Altman \& Egger, 2001). However as we still took an end200 line measure (although as we could not be sure the location was identical and therefore the data 201 were not included in the difference-in-differences analysis) we do not use the term attrition in this 202 paper. It is also important to note that a few of the water intakes could not be unambiguously 203 assigned to control or treatment (for example there are two cases in which one intake supplied two 204 communities, one of which was treatment and the other control); these have been excluded from 205 the RCT analysis. 
207 The principal metric recorded was Escherichia coli colony forming unit concentration (CFUs) in 208 water samples. E. coli concentration, along with that of other non-E. coli bacteria belonging to the 209 coliform group, was quantified using the Coliscan Easygel method (Micrology Labs, Goshen, IN, USA). Coliscan Easygel allows enumeration of coliforms as after incubation E. coli colonies appear purple, blue-purple or dark blue due to metabolism of both beta-galactosidase and betaglucuronidase. Other non- $E$. coli coliforms are pink based upon metabolism of beta-galactosidase only. Colonies of a blue-green or sky blue color (metabolism of beta-glucuronidase only) and white colonies were not counted (Micrology Labs, 2016). The Easygel method (which uses only $5 \mathrm{ml}$ of water per sample) does not comply with the World Health Organization's 100ml standard for coliform monitoring but studies have shown that it is reasonably robust and not susceptible to false negatives (Chuang, Trottier \& Murcott, 2011). This method had been selected by Natura due to the logistical challenges with using alternative methods such as membrane filtration in the remote and low-resource context of the study area (many sites are reachable only with difficult drives and long walks). When we modified the protocol in 2015 (to overcome some of the limitations of the 2010 protocol), we elected to retain the method for the same reason and to ensure data were comparable as possible.

In 2010, one sample was placed into sterile Coliscan Easygel sampling flasks (35ml) taking care to avoid any external contamination. Up to two days later (but normally on the same day) the Natura team then inoculated Easygel Petri dishes using $5 \mathrm{ml}$ of the water from each flask. After solidification the Petri dishes were sealed and incubated at ambient temperature for 48 hours, after which numbers of E. coli and other non-E. coli coliform CFUs were counted.

In 2015, four separate samples were taken using sterile Coliscan Easygel sampling flasks (35ml each) and placed on ice within 1 hour of sampling. Within 6 hours of sampling (although generally within 4) we produced Easygel Petri dishes using $5 \mathrm{ml}$ of water from each flask as inoculum. After solidification we sealed the Petri dishes and incubated them for 24 hours at $35-37^{\circ} \mathrm{C}$ in a portable incubator (NQ28 model, Darwin Chambers, St Louis, MO, USA). In locations where no mains electricity was available we maintained a constant incubation temperature through use of a $12 \mathrm{~V}$ vehicle power supply or supply from a car battery. After incubation we counted E. coli and other non-E. coli coliform CFUs. 
236 In 2015 we also measured in each site a number of physico-chemical parameters of water: 237 temperature, dissolved oxygen in $\mathrm{mg} / \mathrm{l}$ and per cent of saturation value, $\mathrm{pH}$, salinity and 238 conductivity in each site with an HQ40d portable multi-parameter meter and IntelliCAL LDO101, 239 PHC101 and CDC401 rugged probes respectively (HACH Company, Loveland, CO, USA). We 240 measured turbidity in formazin attenuation units through the use of a DR/850 colorimeter $(\mathrm{HACH}$ 241 Company, Loveland, CO, USA). Additionally, at the intake sites, we recorded other variables that 242 may predict $E$. coli concentration, including the presence or absence of cattle (judged based upon 243 presence of faeces, hoof prints, or cattle paths recently used) and the presence or absence of cattle 244 faeces in the riparian forest, in the water, or on banks. Some were recorded at the intake itself and 245 others along a 10m transect upstream (uphill in the case of intakes in springs) of the intake. Details 246 of all monitored variables are available in Table S3.

247 We used Natura's community database to determine which intakes supplied treatment or control 248 communities (we did not have this information when conducting field sampling to avoid any 249 observer bias effects). We used GIS software (ArcGIS 10.2, ESRI, Redlands, CA, USA) and 250 Natura's shapefiles to calculate the percentage of eligible land in each community which was 251 enrolled in Watershared agreements (we compared this percentage between treatment and control 252 communities), and which monitored intakes fell within land enrolled in Watershared agreements. 253 We used data held by Natura to confirm which of these intakes were in agreements which had 254 been compliant with the agreements according to Natura's observations. In a number of the earliest 255 sites monitored during 2015 we accidentally disturbed the sediment in the water intake while 256 taking samples; sites in which this happened were recorded as such.

\section{Balance achieved in the allocation of control and treatment}

258

259

260

261

262

263

264

265
At baseline Natura collected a number of variables at the community level. Two of these (mean number of cows per person in the community, and number of households in the community; both blocked into two groups) were used in the stratification to allocate communities to control or treatment. We explored the balance achieved at baseline for measured variables which may affect the outcome of interest ( $E$. coli contamination at end-line) using standardized mean differences between treatment and control estimated in the $\mathrm{R}$ cobalt package (Greifer, 2018). Included variables were those used in the stratification, time from community centre to hospital (a proxy for remoteness), turbidity and the baseline measure of $E$. coli water contamination. Mean differences 
266 were standardized using pooled standard deviations (Fig. 3). Looking at all 120 communities

267 monitored at baseline, variables appear quite well balanced (all close to or $<0.25$ pooled standard 268 deviation units).

269 However, there is less balance between control and treatment at baseline when just the sites for 270 which we have comparable data for baseline and end-line (i.e. excluding all sites for which we 271 were not $100 \%$ sure that water quality was measured at the same location). When the baseline 272 conditions for these 83 sites in 47 communities are compared, it is clear an imbalance has been 273 introduced in a number of variables. In particular, the remaining control sites had substantially

274 higher E. coli contamination) at baseline and were in more remote communities.

\section{Statistical analysis}

276 We used generalized linear mixed model (GLMMs) to investigate whether features of 277 Watershared agreements (e.g. cattle exclusion, absence of faeces) have a measurable impact on 278 water quality at a site accounting for other predictors. For this we used the much richer 2015 data. 279 We used the glmmADMB package in R (Fournier et al., 2012; R Development Core Team, 2014; 280 Skaug et al., 2016) to produce GLMMs predicting E. coli concentrations, specifying a negative binomial error structure and log-link. We included the water system identifier throughout as a random effect, as measurement at an intake and then a tap supplied by that intake represents repeated measures of the same water system. The unit of analysis is therefore the water system. We used model selection based upon comparisons of the Akaike's Information Criterion (AIC) and compared relative goodness of models through Akaike weighting. We then determined 95\% confidence intervals for predictors in the principal model of interest. For this analysis we used all sites monitored which had a complete set of predictors, with the exception of a single site where the community collect water from a river with a catchment size of $9768 \mathrm{~km}^{2}$, meaning this site is qualitatively different from all other sites (water systems $\mathrm{N}=124$ ). For predictor variable selection we first removed closely correlated predictors and then classified variables we considered likely to be important in predicting E. coli concentration (Table 1). We associated predictor data relating to intake features with both intakes and their respective associated taps. We then produced GLMMs for all purely biophysical traits of sites, while also including all 2-way and 3-way interactions between temperature, $\mathrm{pH}$, and salinity (Table $\mathrm{S} 4$ a). To determine intervention effectiveness, we then added features that related directly to the intervention (cattle access, whether 
296 the site was in a level 1 Watershared agreement, and faeces presence) and again conducted model 297 selection based on AIC minimization (See Table S4 b).

298 We used two approaches to explore whether the implementation of Watershared in treatment 299 communities resulted in an improvement in water quality relative to control communities. In the 300 first approach (evaluating the difference-in-differences from 2010 and 2015 between treatment 301 and control sites), we only included the subset of sites where the sample locations remained the 302 same between 2010 and 2015 and the intake is unambiguously associated with a treatment or 303 control community ( site $\mathrm{N}=83$, communities $\mathrm{N}=47$ ). While we use the term difference-indifferences analysis to refer to this analysis, we note that we do not use the standard difference-indifferences estimator, but take a panel approach and include the baseline outcome value as a covariate (Gelman \& Hill, 2007). This approach is considered more appropriate especially if autocorrelation is low and has greater power (McKenzie, 2012). As the balance check suggested that the reduction in sites had resulted in a lack of balance in pre-existing contamination we performed a matched analysis. Sites were matched on the baseline E. coli measure using genetic matching in the R MatchIt package (Ho et al., 2011). Using the weighting from this matched data we then estimated a differences-in-differences GLMM with E. coli concentration in 2015 as the response variable and site treatment status (whether a site is in a control or treatment community) and 2010 E. coli concentration as potential predictors. Retention of the 2010 E. coli count controlled for the different pre-existing levels of contamination within the matched data set. We also included an interaction term between 2010 E. coli concentration and site treatment status (if this interaction were a significant predictor, this would represent a significant effect of the intervention on water quality). Given the different volume of water sampled in 2010 (5ml) and $2015(20 \mathrm{ml})$, we included an offset term of $\log _{\mathrm{e}}(4)$ in each of the models to ensure equivalence between 2010 and 2015 E. coli CFU counts. We also included water system as a random effect to account for the tap and intake measures. This model was fitted using the glmmTMB package in $\mathrm{R}$ (Brooks et al., 2017) as glmmADMB does not accommodate weights. To account for taps and intakes being connected we included water system as a random effect.

323 In the second approach (evaluating at end-line only) E. coli concentrations in 2015 for all sites 324 (site $\mathrm{N}=228$, community $\mathrm{N}=116$ ) measured were used (regardless of whether we had baseline 325 water quality values measured at the identical location). Again the model was fitted in glmmTMB 
326

327

328

329

330

331

332

333

334

335

336

337

338

339

340

341

342

343

344

345

346

347

348

349

350

351

352

353

354

with site treatment status as the predictor of interest but also including the water source (spring or stream) and data collection point (tap or intake) to control for any differences in these. For both analyses we excluded two sites where water was collected from roofs rather than streams or springs. We accounted for some communities having more than one water system measured by including water system and community as a random effect.

To establish whether in practice land use differs between treatment and control communities, we also determined (for all intakes monitored in 2015 for which data on cattle access is available) whether relative proportions of intake sites protected from cattle differed between the treatment and control communities. We tested for a significant difference using a chi-squared test.

\section{Results}

Cattle faeces in water is one of the significant predictors of E. coli concentration at the local scale

E. coli concentration in 2015 (water systems $\mathrm{N}=124$ ) is significantly predicted by a number of variables (Fig. 4). The details of model selection can be seen in Table S4a (for purely biophysical model selection) and Table S4b for model selection including parameters relating directly to the intervention. Intakes are significantly more contaminated than taps, sites associated with stream intakes are significantly more contaminated than sites associated with spring intakes, and turbidity and disturbance of the sediment by the research team during sampling are both also associated with higher recorded contamination. In terms of variables directly connected to the intervention, the presence of cattle faeces in or close to the water is a significant predictor of contamination. Although faeces presence in the wider forest shows a positive trend, it is not significant at 95\% CI. Details of the model can be found in Table S4c.

\section{The intervention had no significant effect on $E$. coli concentration at the landscape scale}

We analyze the RCT in two ways. In the first (difference-in-differences; Fig. 5) we used weights derived from genetic matching the communities based on the E. coli count in 2010 and only the sub-sample of communities where we are certain water sampling locations are the same in 2010 and 2015 ( sites $\mathrm{N}=83$, communities $\mathrm{N}=47$ ). The weighting strongly downweighted 2 communities $(\mathrm{w}=0.19)$, moderately upweighted $9(\mathrm{w}=1.19)$, strongly upweighted $1(\mathrm{w}=1.5)$ and did not change the relative weighting of the remaining communities. We include E. coli count in 2010 as a 
355

356

357

358

359

360

361

362

363

364

365

366

367

368

369

370

371

372

373

374

375

376

377

378

379

380

381

382

383

predictor to control for sites with naturally higher contamination (e.g. streams rather than springs).

Results from a negative binomial GLM show no significant effect of a site being in a control or treatment community on $E$. coli concentration in 2015. This is because there is no significant interaction between RCT status and E. coli concentration in 2010, meaning that the rate of change in E. coli concentration between 2010 and 2015 is not significantly different in sites associated with treatment or control communities.

In the second analysis we analyse $E$. coli at end-line only (levels in 2015) again using a negative binomial GLM ( all these sites we include important predictors of water quality from Fig. 4. The results show that while taps had significantly lower contamination than intakes and springs lower contamination than streams there was no significant effect of treatment (Fig. 6). Taken together both analyses together show that, using the robust RCT design and both the baseline and end-line datasets, we did not find a significant effect of the intervention on E. coli concentration at the landscape scale.

Uptake was low, highly variable and treatment and control communities do not differ with respect to protection of intakes from cattle.

In treatment communities (where every household was offered the opportunity to enrol land) a low proportion of land eligible to be enrolled in Watershared agreements was actually enrolled, and this proportion was highly variable between communities (Fig 7: range from 0-18\% with a median uptake of $2.5 \%)$. There is no significant difference $(\mathrm{N}=129 ; \mathrm{p}=0.97$; chi-squared test) between the number of intakes protected from cattle in control and treatment community sites. Water intakes in both control and treatment communities tend to be protected from cattle $(61 \%$ and $62 \%$ of intakes respectively) despite only a quarter of intakes being in compliant level 1 areas (Table 2).

\section{Discussion}

\section{Did Watershared improve water quality?}

We show that presence of cattle faeces in water or on the stream banks results in higher E. coli contamination at individual sites. This suggests that excluding cattle from water sources (one of the key actions Watershared seeks to incentivize) can contribute to improving water quality. This should perhaps not be surprising given that fresh cattle faeces can have more than $10^{8} \mathrm{~kg}{ }^{1}$ colony forming units (Weaver, Entry \& Graves, 2005). However, the presence of cattle faeces is only one 
384 predictor of water quality. Intakes fed by streams were much more contaminated than those fed by 385 springs, as could have been predicted (Howell, Coyne \& Cornelius, 1995; WaterAid, 2013). 386 Indeed, the Millennium Development Goal definition of an improved water source allows some 387 springs to be considered improved without further chemical treatment while no stream or river 388 intakes can (Bain et al., 2014b). We also found that intakes were more heavily contaminated than 389 390 taps. This suggests that although the sedimentation and filtration chambers in many of the water systems may not always be effective, they have at least some positive effect on water quality. It is unsurprising that turbidity was an important predictor as this is a well-known as a predictor of $E$. coli contamination (LeChevallier, Evans \& Seidler, 1981).

Despite finding evidence that excluding cattle from riparian forests had a significant impact on water quality at the local scale, both the RCT analyses (comparing E. coli contamination between treatment and control communities) showed no evidence of an effect at the landscape scale.

396

397

398

399

400

401

402

403

404

405

406

407

408

409

410

411

412

413

There is therefore an apparent paradox in that the intervention incentivised (excluding cattle) does apparently improve water quality but the program has not had an impact at the landscape scale. It is possible that there has not been sufficient time between implementation of the intervention and subsequent evaluation for differences to become apparent. Some of the Watershared areas included in the analysis had been enrolled in the latter part of 2014, hence in some cases only a few months before the end-line monitoring was undertaken. It is well known that E. coli can persist in freshwater sediments for long periods of time (Pachepsky \& Shelton, 2011; Cho et al., 2016). However, we argue that features of the way in which the PES program was implemented in the area meant that it was highly likely that no difference would be detected between control and treatment.

Firstly, a very low percentage of eligible land was enrolled in Watershared agreements (the median uptake of enrolled land was $2.5 \%$ of eligible land in treatment communities). In addition, GIS analysis has shown that much of the land which was enrolled could not influence water quality at the intake or tap because it was situated in a different catchment (Pynegar 2018). Livestock-derived E. coli can enter water intakes through a number of routes including overland flow and movement of groundwater (Oliver et al., 2010), and not solely through direct deposition which is what the Watershared agreements try to prevent. The small areas conserved at or above the intakes may well have reduced faeces presence and so reduced E. coli concentration at these sites. However, 
414 upstream or uphill of these intakes contamination may have continued to enter water bodies

415 through multiple routes. Instructively, evidence from a 26-year-old conservation area in the 416 community of La Aguada, near to our study area, shows that despite the $20 \%$ of the catchment

417 nearest to the intake being under conservation with cattle excluded (R. Rueda, pers. comm.), the 418 water remains contaminated (Pynegar 2018).

419 Secondly, the iteration of the Watershared intervention that we studied did not oblige, or even 420 provide extra incentives, for landowners to conserve land surrounding or in the same catchment as 421 monitored intakes. Farmers were free to enrol any land which met the criteria (forest within 100m 422 of a stream or spring). The intervention was not spatially targeted towards areas critical for 423 community water supplies, and in fact only 16 of the 68 water intakes in treatment communities 424 were located inside enrolled and compliant parcels of land. Also, many communities in the study 425 area had previously excluded cattle from water intakes independently of the Watershared program, 426 meaning there is no significant difference in the proportion of intakes protected from cattle 427 between treatment and control communities.

428 Finally, not all the land enrolled in Watershared agreements will represent additional conservation. 429 There is a large body of evidence showing that adverse participant selection in PES programs 430 means that a significant proportion of land enrolled would have been conserved in the absence of 431 the incentives (Börner et al., 2017). There has been concern about the extent to which conservation 432 funded under the Watershared programme will represent additional conservation since the early 433 days of the scheme (Robertson \& Wunder, 2005; Asquith, Vargas \& Wunder, 2008). Best 434 estimates for the Watershared intervention suggest that only about one third of level 1 agreements 435 have resulted in cattle being excluded from land which they would have otherwise been using 436 (Bottazzi et al., 2018).

437 Given the very low uptake of Watershared agreements, the lack of targeting of the land enrolled, 438 and the fact that (like in any PES programme) not all the land enrolled represents additional 439 conservation, it is perhaps not surprising that we did not detect an impact of the intervention on 440 water quality at the landscape scale.

441 How would Watershared have to change to result in a significant impact on water quality? 
442 Some of the reasons why Watershared did not produce landscape-scale impacts on water quality 443 relate to commonly recognised issues in PES implementation. First, the link between the land use 444 incentivised (the proxy) and the ecosystem service desired is often weak and poorly understood 445 (Jack, Kousky and Sims 2008). In the case of Watershared, it is unclear how much land in a 446 catchment would need to be protected, where, and over what timescale, to obtain a significant 447 improvement in water quality at the landscape or even the catchment scale. Second, the marginal 448 benefits from service provision (or in this case the land use proxy for service provision) are highly 449 spatially heterogeneous. Land enrolled directly upstream of intakes will probably have an effect 450 on monitored water quality while areas under conservation elsewhere (for example below the water 451 intake) obviously cannot. In such cases, spatial targeting and differentiated payments would likely 452 increase program efficiency (Ezzine-de-Blas et al., 2016).

453 Both theory (Persson \& Alpízar, 2013) and empirical research on PES programmes (Arriagada, 454 Sills, Pattanayak, \& Ferraro, 2009) suggest that low levels of payments result in low uptake. It thus 455 seems likely that higher Watershared payments would have ensured that a higher proportion of 456 eligible land was enrolled. It is difficult to directly compare payments in Watershared with those 457 in related programmes both because of the payment structure (in Watershared participants are paid 458 an enrolling fee plus a per hectare payment) and because a dollar is worth more in some countries 459 than others. However the per-hectare payments in Watershared is certainly lower than other 460 payments for watershed services-type programs in Latin America: for example Mexico's PSA-H 461 program pays $27 \mathrm{USD} /$ hectare/year for primary forest and $36 \mathrm{USD} / \mathrm{ha} / \mathrm{year}$ for cloud forest 462 (Muñoz-Piña et al. 2008) while Costa Rica's national PES pays 45 to 163 USD/hectare/year 463 (Wunder, Engel \& Pagiola 2008). The Ugandan PES program analysed in the RCT by 464 Jayachandran et al. (2017) paid landowners 28 USD per year per hectare of forest. Bottazzi et al. 465 (2018) show that those signing Watershared agreements have multiple motivations for doing so. 466 To ensure that areas most valuable in terms of their potential ecosystem service provision were 467 enrolled would require targeting. However such targeting would increase the complexity and 468 transaction costs of the program (Jack, Kousky \& Sims, 2008) and poses potential issues in terms 469 of perceived fairness locally.

470 There is also likely to be a limit to the impact that livestock exclusion can achieve, and this will 471 depend on the extent to which faecal contamination derives from other sources such as wildlife, 
472 inadequate sanitation infrastructure, spreading of manure on agricultural land, or from open

473 defecation. Those involved in promoting similar interventions should check the extent to which

474 cattle contamination is indeed the driver of microbial water quality issues in the region, perhaps

475 using genetic testing of E. coli (Carson et al., 2001). Context-appropriate engineering solutions,

476 such as protection of springs used for drinking water (Kremer et al., 2011), use of springs rather

477 than streams as drinking water sources, construction of filtration systems, or introduction of

478 household-level interventions (Clasen et al., 2007), may be more effective at improving water

479 quality than livestock exclusions. Such solutions however do not provide the desired co-benefits

480 of the intervention, such as forest carbon storage, biodiversity conservation, and increases in local

481 incomes. Future work may aim to combine both conservation and engineering solutions and

482 involve more direct conservation actions such as purchase or rent of particularly sensitive or 483 important catchments.

484 Did the RCT enable robust evaluation of the efficacy of the Watershared program?

485 Uptake of Watershared agreements was very low (the median \% enrolment of eligible land in 486 treatment communities was just 2.5\%). There was also no targeting of the land enrolled meaning 487 that little of the land enrolled could impact water quality. Although $24 \%$ of the water intakes in 488 treatment communities were in compliant level 1 Watershared agreements, there is no difference 489 in the percentage of water intakes protected from cattle in treatment and control communities. This 490 is because communities protect their water intakes for many reasons and it appears that the 491 intervention was not significantly effective at increasing this level of protection. Therefore, the conclusion we draw from the RCT analysis about the efficacy of Watershared as delivered in this area at influencing water quality at the landscape scale, could equally have been drawn without a large-scale experiment conducted over 5 years. Theory-based impact evaluation (mapping out the causal chain from inputs to outcomes and testing the underlying assumptions; White, 2009) could have been just as effective. The RCT in this case therefore added little to evaluating the impact of this intervention.

Despite the challenges of implementing this RCT, and observation that the same conclusions about programme impact could probably have been made without the RCT, we remain positive about 
502 efficacy of a programme and this is only going to increase. We therefore suggest that those

503 interested in quality impact evaluation of landscape-scale conservation interventions learn from 504 the experience of the Watershared RCT.

505 Lessons learnt from the experience of the Watershared RCT for future evaluations of landscape506 scale conservation interventions

507 The randomisation unit needs to be carefully selected: The choice of randomisation unit in an RCT 508 will influence spillover; the phenomenon in which treatment may affect outcomes in non-treated 509 units resulting in an erroneously low estimate of treatment effect size (Glennerster \& Takavarasha, 510 2013). In the case of the Watershared RCT, randomization was at the level of the community. 511 However for evaluating the impact of the program on water quality, a more appropriate 512 randomization unit would have been the catchment above the intake supplying water to a 513 community. The selection of communities as the randomisation unit in this RCT was problematic 514 because catchments above treatment community water intakes could fall partially within 515 neighbouring treatment communities (or vice versa); potentially resulting in spillover of effects 516 between treatment and control communities (Pynegar 2018). However Watershared was not 517 designed only to impact water quality but also to reduce deforestation, improve forest biodiversity 518 and provide socio-economic benefits (Asquith, 2016). Designing an RCT to evaluate the impact 519 of an intervention on multiple outcomes is inevitably challenging (Pynegar 2018). A future RCT 520 of landscape-scale environmental management interventions should ensure that the randomisation 521 unit is selected to minimise the risk of spillover. This may mean an RCT can only effectively 522 evaluate the impact of one or two outcomes at once.

523 There are difficult decisions to make in selecting sites at which to monitor outcomes: One of the 524 aims of Watershared was to improve the quality of water consumed in communities. The decision 525 was therefore made to measure water quality at the intake and tap serving the largest number of 526 households in each community. Unfortunately, in a significant number of communities, the water 527 intake serving the community had changed over the 5 years of the intervention. At such sites, if 528 end-line data were to be taken from the water system serving the majority of the community, the 529 end-line and baseline data were inevitably not at the same location. These sites thus had to be 530 excluded from the difference-in-differences analysis. By conducting the analysis in two ways (our 531 difference-in-differences analysis for the sub-set of communities where the intake was comparable 
532 across the period and using end-line data only from the full set of communities) we were able to

533 use as much of the data as possible.

534 An RCT is not appropriate unless the intervention is well developed: The substantial investment 535 of time and resources in an RCT means that it is only appropriate when implementers are confident 536 that they have an intervention whose functioning is reasonably well developed (Pattanayak, 2009;

537 Cartwright, 2010). At earlier stages of developing an intervention, formative rather than 538 summative impact evaluation processes might be more appropriate (Rossi, Lipsey \& Freeman, 539 2004). The implementers of Watershared had experimented with versions of the program before 540 implementing the RCT. However in the event, uptake of Watershared was so low that an RCT was 541 not an appropriate method of evaluating its impact on water quality at a landscape scale. Precise 542 levels of uptake cannot be known until the experiment is already set up and the intervention 543 offered, but pilot work (or analysis of the GIS data showing the location of enrolled agreements) 544 might have revealed this low uptake and efforts been made to increase it (by raising the payments 545 offered).

546 Effort should be made to ensure balance between treatment and control in outcomes of interest:

547 In the Watershared RCT, the allocation to treatment and control achieved quite good balance in 548 the variables likely to influence $E$. coli contamination (although when only the subset of sites for 549 which there is a comparable end-line is considered a significant imbalance in baseline values for 550 E. coli contamination between treatment and control was introduced). Of course imperfect balance 551 is a common problem in RCTs and is not a barrier to valid inference (Senn, 2013). We were able 552 to account for the imbalance in our difference-in-differences analysis by matching on baseline $E$. 553 coli values at each site. However to reduce the chance of random allocation to control and 554 treatment resulting in an imbalance in important variables, baseline information on the outcome of 555 interest (in this case E. coli contamination) should be included in the stratification.

556 Care needs to be taken to avoid contamination of the control: In an ideal RCT, there is zero uptake 557 of the intervention in the control group and consistent and high uptake in the treatment community. 558 Unfortunately, in many situations the control is contaminated by information from treatment 559 participants spreading to controls (Torgerson, 2001). In the Watershared RCT there was non-zero 560 uptake among the control communities. In this case, the contamination of the control was due to 561 people living in treatment communities but owning land in treatment communities which they 
562 chose to enrol. This was not noticed during the roll out of the program for two reasons. Firstly, the

563 community boundaries were not available until they were generated (with substantial investment)

564 by our research team in 2017. Secondly, for the technicians involved in day-to-day implementation

565 of Watershared, the detail of where enrolled land occurred relative to treatment and control

566 communities was not a priority. In future, we suggest that those establishing an RCT to evaluate

567 the impact of environmental management interventions at scale ensure they have sufficient

568 research capacity during the implementation phase to monitor the RCT while it is in progress so

569 issues such as this could be avoided.

570 Blinding is unlikely to be fully possible in land-scale scale conservation interventions: Double

571 blinding is considered best practice in RCTs so neither the researcher nor the participants know

572 who has been assigned to the treatment or control group (Glennerster \& Takavarasha, 2013). In

573 the case of the Watershared RCT the researchers scoring the E. coli contamination did not know

574 whether the sample came from a treatment of control community; so blinding was achieved there.

575 However the participants clearly knew they were in a control or treatment community. Those

576 allocated to control or treatment may have different expectations or show different behaviour or

577 effort simply as a consequence of being allocated to a control or treatment group (Chassang, Padró

578 i Miquel \& Snowberg, 2012). Some authors have claimed that these behavioural effects may be

579 large (Bulte et al., 2014) but they have not been extensively studied. They should be considered in

580 the design of any landscape-scale RCT.

\section{Conclusions}

582 There is global interest in PES because it is seen as an efficient way to provide environmental 583 outcomes. The effectiveness of PES in achieving its intended outcomes is fundamentally an 584 empirical question but the quality of the evidence base concerning the delivery of benefits from 585 PES is mixed. There is therefore substantial interest in robust evaluation of the effectiveness of 586 PES programs at delivering outcomes. We conclude that this particular program would require 587 much greater uptake (probably requiring higher payments) and more intensive targeting (which 588 would increase substantially the transaction costs and design complexity of the intervention) to 589 have a significant impact on water quality. However, although this paper presents the results of a 590 Randomised Control Trial (one of the very few implemented to evaluate the impacts of a 591 conservation intervention at scale), these same conclusions could have been drawn without the 
592 RCT. The low uptake of the program and the lack of a difference in water intakes protected from

593 cattle between control and treatment communities make the result of the RCT (no effect of the 594 program detected) inevitable. Randomised Control Trials have the potential to contribute to 595 building the evidence base for understanding the impact of environmental management approaches 596 such as Payments for Ecosystem Services. However, as evidenced by the Watershared experience, 597 they are not straightforward to implement in practice. We hope that by publishing the experience 598 of the Watershared RCT we will encourage future landscape-scale conservation impact 599 evaluations to improve on the use of this evaluation approach in conservation.

\section{Acknowledgements}

601 We thank colleagues at Fundación Natura Bolivia for all of their assistance, contributions and 602 ideas, especially María Teresa Vargas, Tito Vidaurre, Maximo García, Dionicio Toledo, Hugo 603 Vallejos, Miler Guzmán, Antonio Daza, Denis Calderón, Huascar Azurduy, Veronica Chávez and 604 Victoria Aguilera. We are very grateful to Kelsey Jack for initial randomisation and to Dave 605 Chadwick, Prysor Williams, Patrick Bottazzi, Robert Rueda and David Crespo for valued 606 discussion. Sven Wunder and two anonymous reviewers gave very helpful feedback during the 607 review process which substantially improved both the analysis and the framing of this paper. We 608 also thank members of the communities in which we conducted monitoring for their support and 609 permission.

\section{References}

611 Ahmed W., Hodgers L., Sidhu JPS., Toze S. 2012. Fecal indicators and zoonotic pathogens in 612 household drinking water taps fed from rainwater tanks in Southeast Queensland, Australia. 613 Applied and Environmental Microbiology 78:219-226. DOI: 10.1128/AEM.06554-11.

614 Anonymous. 2016.Establishment of buffer strips along watercourses. Available at https://www.gov.uk/guidance/guide-to-cross-compliance-in-england-2016/gaec-1establishment-of-buffer-strips-along-watercourses (accessed August 3, 2016).

617 Arriagada RA., Sills EO., Pattanayak SK., Ferraro PJ. 2009. Combining qualitative and 618 quantitative methods to evaluate participation in Costa Rica's program of payments for 619 environmental services. Journal of Sustainable Forestry 28:343-367. 
620

621

622

Ashbolt N., Grabow W., Snozzi M. 2001. Indicators of microbial water quality. In: Water Quality: Guidelines, Standards and Health. 289-316. DOI: 10.4324/9781315693606.

Asquith NM. 2016. Watershared: Adaptation, mitigation, watershed protection and economic development in Latin America. Climate \& Development Knowledge Network.

Asquith NM., Vargas MT., Wunder S. 2008. Selling two environmental services: In-kind payments for bird habitat and watershed protection in Los Negros, Bolivia. Ecological Economics 65:675-684. DOI: 10.1016/J.ECOLECON.2007.12.014.

Bain R., Cronk R., Hossain R., Bonjour S., Onda K., Wright J., Yang H., Slaymaker T., Hunter P., Prüss-Ustün A., Bartram J. 2014a. Global assessment of exposure to faecal contamination through drinking water based on a systematic review. Tropical Medicine \& International Health 19:917-927. DOI: 10.1111/tmi.12334.

Bain R., Cronk R., Wright J., Yang H., Slaymaker T., Bartram J. 2014b. Fecal Contamination of Drinking-Water in Low- and Middle-Income Countries: A Systematic Review and MetaAnalysis. PLoS Medicine 11:e1001644. DOI: 10.1371/journal.pmed.1001644.

Baylis K., Honey-Rosés J., Börner J., Corbera E., Ezzine-de-Blas D., Ferraro PJ., Lapeyre R., Persson UM., Pfaff A., Wunder S. 2016. Mainstreaming Impact Evaluation in Nature Conservation. Conservation Letters 9:58-64. DOI: 10.1111/conl.12180.

Börner J., Baylis K., Corbera E., Ezzine-de-Blas D., Ferraro PJ., Honey-Rosés J., Lapeyre R., Persson UM., Wunder S. 2016. Emerging Evidence on the Effectiveness of Tropical Forest Conservation. PLOS ONE 11:e0159152. DOI: 10.1371/journal.pone.0159152.

Börner J., Baylis K., Corbera E., Ezzine-de-Blas D., Honey-Rosés J., Persson UM., Wunder S. 2017. The Effectiveness of Payments for Environmental Services. World Development 96:359-374. DOI: 10.1016/j.worlddev.2017.03.020.

Bottazzi P., Vargas Rios MT., Asquith N., Crespo D., Vidaurre T., García M., Miler Guzmán R., Gonzales L., Vallejos H., Pérez Guzman B., Avila Becerra F., Toledo D., Jones JPG. 2017. Baseline and endline socio-economic data from a Randomised Control Trial of the Watershared intervention in the Bolivian Andes. ReShare UK Data Archive. DOI: 10.5255/UKDA-SN-852623. 
648 Bottazzi P., Wiik E., Crespo D., Jones JPG. 2018. Payment for Environmental "Self-Service": 649 Exploring the Links Between Farmers' Motivation and Additionality in a Conservation 650 Incentive Programme in the Bolivian Andes. Ecological Economics 150:11-23. DOI: 651 10.1016/j.ecolecon.2018.03.032.

652

653

654

655

656

657

658

659

660

661

662

663

664

665

666

667

668

669

670

671

672

673

674

675

Bowler DE., Buyung-Ali LM., Healey JR., Jones JPG., Knight TM., Pullin AS. 2012. Does community forest Management provide global environmental benefits and improve local welfare? Frontiers in Ecology and the Environment 10:29-36. DOI: 10.1890/110040.

Brooks ME., Kristensen K., van Benthem KJ., Magnusson A., Berg CW., Nielsen A., Skaug HJ., Mächler M., Bolker BM. 2017. The R journal. The R Journal 9:378-400.

Bruijnzeel LA. 2004. Hydrological functions of tropical forests: not seeing the soil for the trees? Agriculture, Ecosystems \& Environment 104:185-228. DOI: http://dx.doi.org/10.1016/j.agee.2004.01.015.

Bulte E., Beekman G., Di Falco S., Hella J., Lei P. 2014. Behavioral Responses and the Impact of New Agricultural Technologies: Evidence from a Double-blind Field Experiment in Tanzania. American Journal of Agricultural Economics 96:813-830. DOI: 10.1093/ajae/aau015.

Calvet-Mir L., Corbera E., Martin A., Fisher J., Gross-Camp N. 2015. Payments for ecosystem services in the tropics: A closer look at effectiveness and equity. Current Opinion in Environmental Sustainability 14:150-162. DOI: 10.1016/j.cosust.2015.06.001.

Carson CA., Shear BL., Ellersieck MR., Asfaw A. 2001. Identification of Fecal Escherichia coli from Humans and Animals by Ribotyping. Applied and Environmental Microbiology 67:1503-1507. DOI: 10.1128/AEM.67.4.1503-1507.2001.

Cartwright N. 2010. What are randomised controlled trials good for? Philosophical Studies 147:59-70. DOI: 10.1007/s11098-009-9450-2.

Chassang S., Padró i Miquel G., Snowberg E. 2012. Selective Trials: A Principal-Agent Approach to Randomized Controlled Experiments. American Economic Review 102:12791309. DOI: $10.1257 /$ aer.102.4.1279. 
676

677

678

679

680

681

682

683

684

685

686

687

688

689

690

691

692

693

694

695

696

697

698

699

700

701

702

2016. Modeling fate and transport of fecally-derived microorganisms at the watershed scale: State of the science and future opportunities. Water Research 100:38-56. DOI: 10.1016/j.watres.2016.04.064.

Chuang P., Trottier S., Murcott S. 2011. Comparison and verification of four field-based microbiological tests: $\mathrm{H} 2 \mathrm{~S}$ test, Easygel ${ }^{\circledR}$, Colilert ${ }^{\circledR}$, Petrifilm ${ }^{\mathrm{TM}}$. Journal of Water Sanitation and Hygiene for Development 1:68-85.

Clasen T., Cairncross S., Haller L., Bartram J., Walker D. 2007. Cost-effectiveness of water quality interventions for preventing diarrhoeal disease in developing countries. Journal of Water and Health 5:599. DOI: 10.2166/wh.2007.010.

Council of Economic Advisers. 2014. Evaluation as a tool for improving federal programs. In: Economic Report of the President, Together with the Annual Report of the Council of Economic Advisors. Washington DC: U.S. Government Printing Office, 269-298.

Crane SR., Moore JA., Grismer Jr. ME., Milner JR. 1983. Bacterial pollution from agricultural sources: A review. Transactions of the American Society of Agricultural Engineers 26:858866.

Dasgupta S. 2017. Experience or evidence: How do big conservation NGOs make decisions? Mongabay.

Dasgupta S., Gaworecki M., Burivalova Z. 2018. Conservation Effectiveness. Mongabay.

Duchelle A., Wunder S., Martius C. 2018. Understanding what works in forest-based mitigation. Green Climate Fund Independent Evaluation Unit.

Ezzine-de-Blas D., Wunder S., Ruiz-Pérez M., Moreno-Sanchez R del P., Nikolakis W., Wilson P. 2016. Global Patterns in the Implementation of Payments for Environmental Services. PLOS ONE 11:e0149847. DOI: 10.1371/journal.pone.0149847.

Ferraro PJ. 2017. Are payments for ecosystem services benefiting ecosystems and people? In: Kareiva P, Marvier M, Silliman B eds. Effective Conservation Science: Data Not Dogma. New York, NY: Oxford University Press, 159-166. DOI: 10.1093/oso/9780198808978.001.0001. 
703 Ferraro PJ., Pattanayak SK. 2006. Money for Nothing? A Call for Empirical Evaluation of 704 Biodiversity Conservation Investments. PLoS Biol 4:e105. DOI:

$705 \quad$ 10.1371/journal.pbio.0040105.

706 Fournier DA., Skaug HJ., Ancheta J., Ianelli J., Magnusson A., Maunder MN., Nielsen A., Sibert 707 J. 2012. AD Model Builder: using automatic differentiation for statistical inference of 708 highly parameterized complex nonlinear models. Optimization Methods and Software 709

710

711

712

713

714

715

716

717

718

719

720

721

722

723

724

725

726

727

728

729 27:233-249. DOI: 10.1080/10556788.2011.597854.

Gelman A., Hill J. 2007. Data analysis using regression and multilevel/hierarchical models. Cambridge University Press.

Glennerster R., Takavarasha K. 2013. Running Randomized Evaluations: A Practical Guide. Princeton, USA: Princeton University Press.

Greenstone M., Gayer T. 2009. Quasi-experimental and experimental approaches to environmental economics. Journal of Environmental Economics and Management 57:2144. DOI: 10.1016/j.jeem.2008.02.004.

Greifer N. 2018. cobalt: Covariate Balance Tables and Plots. In: R package version 3.3.0.

Grima N., Singh SJ., Smetschka B., Ringhofer L. 2016. Payment for Ecosystem Services (PES) in Latin America: Analysing the performance of 40 case studies. Ecosystem Services 17:2432. DOI: 10.1016/J.ECOSER.2015.11.010.

Ho DE., Imai K., King G., Stuart EA. 2011. MatchIt: Nonparametric Preprocessing for Parametric Causal Inference. JSS Journal of Statistical Software 42.

Howell JM., Coyne MS., Cornelius P. 1995. Fecal Bacteria in Agricultural Waters of the Bluegrass Region of Kentucky. Journal of Environment Quality 24:411. DOI: $10.2134 /$ jeq1995.00472425002400030003x.

Jack BK., Kousky C., Sims KRE. 2008. Designing payments for ecosystem services: Lessons from previous experience with incentive-based mechanisms. Proceedings of the National Academy of Sciences 105:9465-9470. DOI: 10.1073/pnas.0705503104.

Jayachandran S., de Laat J., Lambin EF., Stanton CY., Audy R., Thomas NE. 2017. Cash for 
730

731

732

733

734

735

736

737

738

739

740

741

742

743

744

745

746

747

748

749

750

751

752

753

754

755

756

carbon: A randomized trial of payments for ecosystem services to reduce deforestation. Science 357:267-273. DOI: 10.1126/science.aan0568.

Jüni P., Altman DG., Egger M. 2001. Assessing the quality of controlled clinical trials. BMJ 323.

Keeler BL., Polasky S., Brauman KA., Johnson KA., Finlay JC., O’Neill A., Kovacs K., Dalzell B. 2012. Linking water quality and well-being for improved assessment and valuation of ecosystem services. Proceedings of the National Academy of Sciences of the United States of America 109:18619-18624. DOI: 10.1073/pnas.1215991109.

Kremer M., Leino J., Miguel E., Zwane AP. 2011. Spring cleaning: Rural water impacts, valuation, and property rights institutions. Quarterly Journal of Economics 126:145-205. DOI: $10.1093 / \mathrm{qje} / \mathrm{qjq} 010$.

LeChevallier MW., Evans TM., Seidler RJ. 1981. Effect of turbidity on chlorination efficiency and bacterial persistence in drinking water. Applied and Environmental Microbiology 42:159-167.

Leclerc H., Mossel D a., Edberg SC., Struijk CB. 2001. Advances in the bacteriology of the coliform group: their suitability as markers of microbial water safety. Annual review of microbiology 55:201-234. DOI: 10.1146/annurev.micro.55.1.201.

Martin-Ortega J., Ojea E., Roux C. 2013. Payments for Water Ecosystem Services in Latin America: A literature review and conceptual model. Ecosystem Services 6:122-132.

McKenzie D. 2012. Beyond baseline and follow-up: The case for more $\mathrm{T}$ in experiments. Journal of Development Economics 99:210-221. DOI: 10.1016/J.JDEVECO.2012.01.002.

Micrology Labs. 2016. Detection of Waterborne Coliforms and E. coli with Coliscan Easygel.

Miteva DA., Pattanayak SK., Ferraro PJ. 2012. Evaluation of biodiversity policy instruments: What works and what doesn't? Oxford Review of Economic Policy 28:69-92. DOI: 10.1093/oxrep/grs009.

Mooney C. 2016. A cheap, simple experiment just found a very effective way to slow deforestation. The Washington Post.

Muñoz-Piña C., Guevara A., Torres JM., Braña J. 2008. Paying for the hydrological services of 
757

758

759

760

761

762

763

764

765

766

767

768

769

770

771

772

773

774

775

776

777

778

779

780

781

782

783

784

Mexico's forests: Analysis, negotiations and results. Ecological Economics 65:725-736. DOI: 10.1016/j.ecolecon.2007.07.031.

Naeem S., Ingram JC., Varga A., Agardy T., Barten P., Bennett G., Bloomgarden E., Bremer LL., Burkill P., Cattau M. 2015. Get the science right when paying for nature's services. science 347:1206-1207.

Oliver DM., Page T., Hodgson CJ., Heathwaite AL., Chadwick DR., Fish RD., Winter M. 2010. Development and testing of a risk indexing framework to determine field-scale critical source areas of faecal bacteria on grassland. Environmental Modelling and Software 25:503-512. DOI: 10.1016/j.envsoft.2009.10.003.

Pachepsky YA., Shelton DR. 2011. Escherichia coli and Fecal Coliforms in Freshwater and Estuarine Sediments. Critical Reviews in Environmental Science and Technology 41:10671110. DOI: $10.1080 / 10643380903392718$.

Pattanayak SK. 2009. Rough Guide to Impact Evaluation of Environmental and Development Programs. Kathmandu, Nepal.

Pattanayak SK., Wunder S., Ferraro PJ. 2010. Show me the money: Do payments supply environmental services in developing countries? Review of Environmental Economics and Policy 4:254-274. DOI: 10.1093/reep/req006.

Persson UM., Alpízar F. 2013. Conditional Cash Transfers and Payments for Environmental Services - A Conceptual Framework for Explaining and Judging Differences in Outcomes. World Development 43:124-137. DOI: 10.1016/j.worlddev.2012.10.006.

Ponette-González AG., Brauman KA., Marín-Spiotta E., Farley KA., Weathers KC., Young KR., Curran LM. 2015. Managing water services in tropical regions: From land cover proxies to hydrologic fluxes. Ambio 44:367-375. DOI: 10.1007/s13280-014-0578-8.

Prüss-Ustün A., Bartram J., Clasen T., Colford JM., Cumming O., Curtis V., Bonjour S., Dangour AD., De France J., Fewtrell L., Freeman MC., Gordon B., Hunter PR., Johnston RB., Mathers C., Mäusezahl D., Medlicott K., Neira M., Stocks M., Wolf J., Cairncross S. 2014. Burden of disease from inadequate water, sanitation and hygiene in low- and middleincome settings: a retrospective analysis of data from 145 countries. Tropical Medicine \& 
786

787

788

789

790

791

792

793

794

795

796

797

798

799

800

801

802

803

804

805

806

807

808

809

810

811

Puri J., Nath M., Bhatia R., Glew L. 2016. Examining the evidence base for forest conservation interventions. New Delhi.

R Development Core Team. 2014. R: A language and environment for statistical computing.

Richards S., Paterson E., Withers PJA., Stutter M. 2016. Septic tank discharges as multipollutant hotspots in catchments. Science of the Total Environment 542:854-863. DOI: 10.1016/j.scitotenv.2015.10.160.

Robertson N., Wunder S. 2005. Fresh Tracks in the Forest: Assessing Incipient Payments For Enivronmental Services Initiatives in Bolivia. Jakarta: CIFOR.

Rossi P., Lipsey M., Freeman H. 2004. Evaluation: a Systematic Approach. Thousand Oaks, CA: SAGE Publications.

Rubin DB. 1974. Estimating causal effects of treatments in randomized and nonrandomized studies. Journal of Educational Psychology 66:688-701. DOI: 10.1037/h0037350.

Salzman J., Bennett G., Carroll N., Goldstein A., Jenkins M. 2018. The global status and trends of Payments for Ecosystem Services. Nature Sustainability 1:136-144. DOI: 10.1038/s41893-018-0033-0.

Samii C., Lisiecki M., Kulkarni P., Paler L., Chavis L. 2014. Effects of Payment for Environmental Services (PES) on Deforestation and Poverty in Low and Middle Income Countries: A Systematic Review. Campbell Systematic Reviews 10. DOI: 10.4073/csr.2014.11.

Senn S. 2013. Seven myths of randomisation in clinical trials. Statistics in Medicine 32:14391450. DOI: $10.1002 / \operatorname{sim} .5713$.

Skaug H., Fournier D., Bolker B., Magnusson A., Nielsen A. 2014. Generalized Linear Mixed Models using AD Model Builder.

Spears D., Ghosh A., Cumming O. 2013. Open Defecation and Childhood Stunting in India: An Ecological Analysis of New Data from 112 Districts. PLoS ONE 8:e73784. DOI: 10.1371/journal.pone.0073784. 
812 Sunohara MD., Topp E., Wilkes G., Gottschall N., Neumann N., Ruecker N., Jones TH., Edge

813

814

815

816

817

818

819

820

821

822

823

824

825

826

827

828

829

830

831

832

833

834

835

TA., Marti R., Lapen DR. 2012. Impact of riparian zone protection from cattle on nutrient, bacteria, F-coliphage, and loading of an intermittent stream. Journal of Environmental Quality 41:1301-1314. DOI: 10.2134/jeq2011.0407.

Sutherland WJ., Wordley CFR. 2017. Evidence complacency hampers conservation. Nature Ecology \& Evolution 1:1215-1216. DOI: 10.1038/s41559-017-0244-1.

Torgerson DJ. 2001. Contamination in trials: is cluster randomisation the answer? BMJ 322.

Waeber PO., Wilmé L., Mercier JR., Camara C., Lowry PP. 2016. How effective have thirty years of internationally driven conservation and development efforts been in Madagascar? PLoS ONE 11. DOI: 10.1371/journal.pone.0161115.

WaterAid. 2013. Gravity-fed Schemes. WaterAid Technology Briefs.

Weaver RW., Entry JA., Graves A. 2005. Numbers of fecal streptococci and Escherichia coli in fresh and dry cattle, horse, and sheep manure. Canadian Journal of Microbiology 51:847851. DOI: $10.1139 / \mathrm{w} 05-071$.

White H. 2009. Theory-Based Impact Evaluation: Principles and Practice.

White H. 2013. An introduction to the use of randomised control trials to evaluate development interventions. Journal of Development Effectiveness 5:30-49. DOI:

10.1080/19439342.2013.764652.

Wunder S. 2015. Revisiting the concept of payments for environmental services. Ecological Economics 117:234-243.

Wunder S., Engel S., Pagiola S. 2008. Taking stock: A comparative analysis of payments for environmental services programs in developed and developing countries. Ecological Economics 65:834-852. 


\section{Figure 1}

Map of the study area.

a) Locations of the 65 treatment communities (Watershared agreements offered) and 64 control communities (Watershared agreements not offered) within the Río Grande Valles Cruceños Natural Integrated Management Area (ANMI RG-VC). b) Location of the ANMI RG-VC protected area within Bolivia 


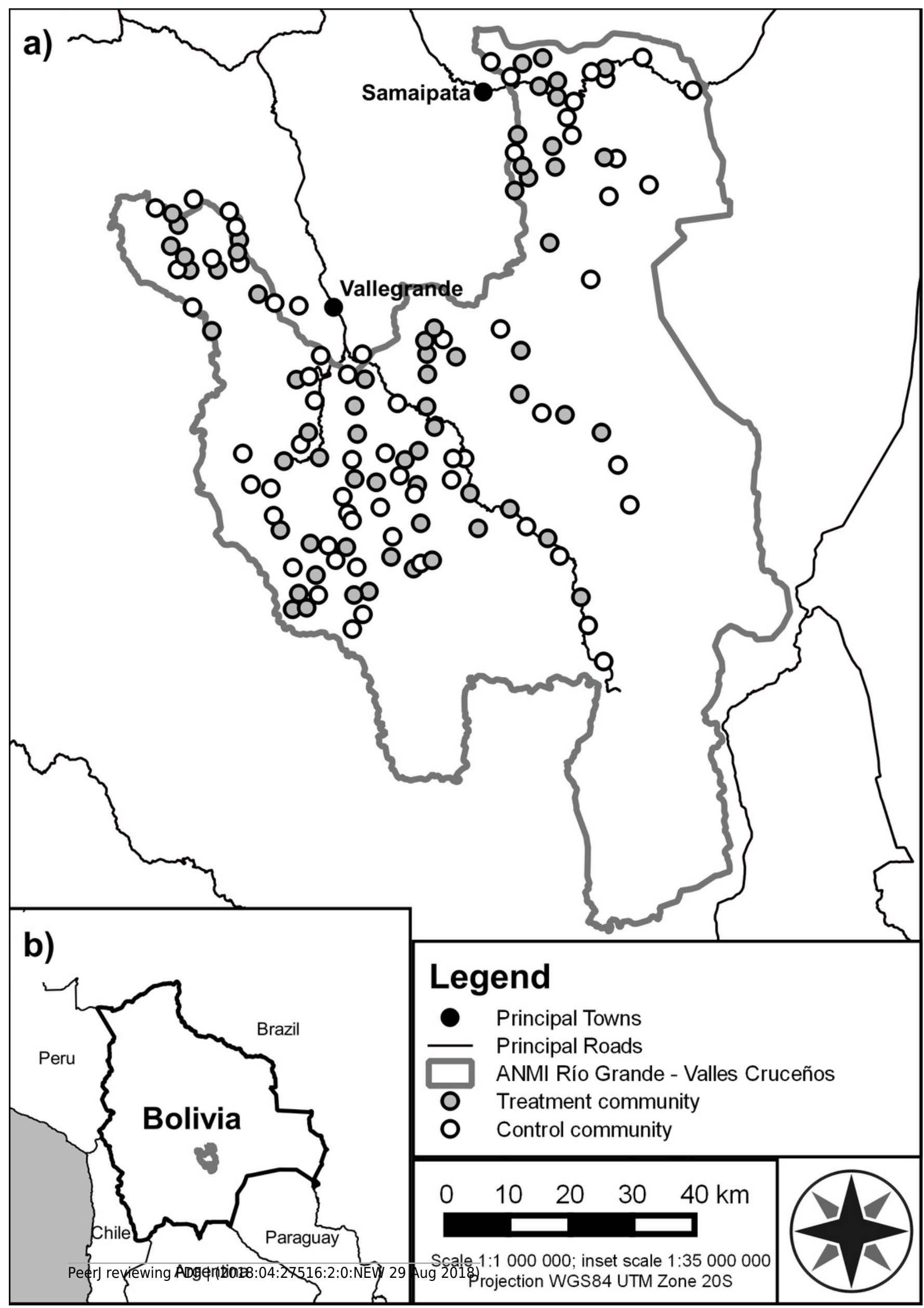


Figure 2

Schematic of an example community with two water intakes showing locations of intake and tap sampling sites.

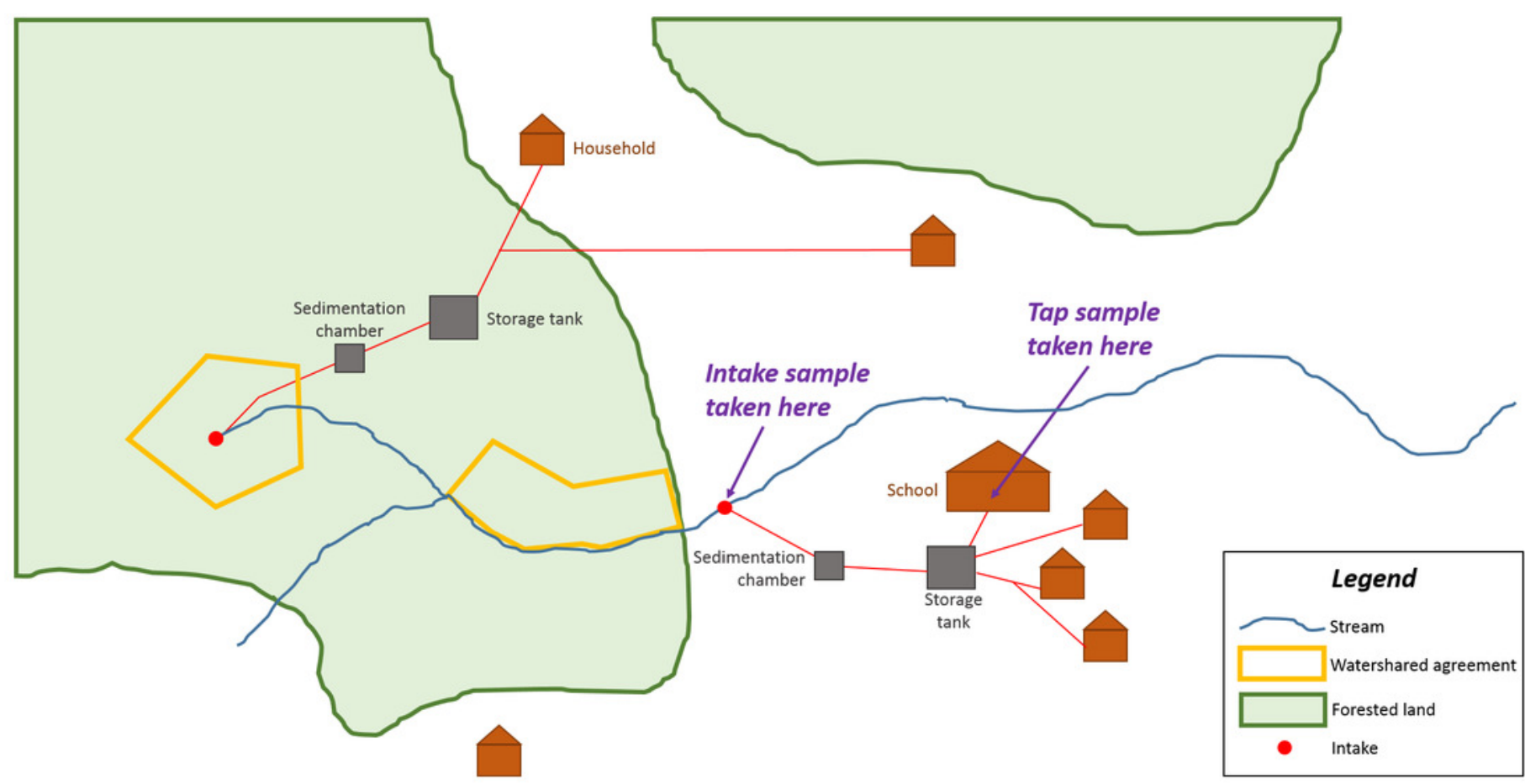




\section{Figure 3 (on next page)}

Balance plot showing the standardized absolute mean differences between control and treatment communities at baseline.

Key baseline variables likely to influence end-line microbial water quality are shown both for the 120 communities where water quality was monitored at baseline, and the subset of 47 communities for which the monitoring location remained the same between baseline and end-line data collection. The loss of sites resulted in a substantial increase in imbalance for two variables (especially in baseline $E$. coli contamination). The dashed line indicates acceptable balance $(<0.25$ pooled standard deviation units). 
Number of households -

Cows per household -

E. coli CFU in 2010 -

Time to hospital -

Turbidity -

0.0

0.2

0.4

0.6

\section{Balance}

- All communities

with baseline water data Subset of communities with comparable end-line

\section{Standardized aloselutemean difference}




\section{Figure 4 (on next page)}

The effect of site features which predict $2015 \mathrm{E}$. coli concentration.

Error bars show $95 \%$ confidence intervals. This shows the results of the most highly supported GLMM (see Tables S4a, b and c for model selection tables and details of the presented model). Water systems $\mathrm{N}=124$. 
Log-transformed E. coli CFU concentration

Spring intake compared with stream intake

Turbidity (FAU/100)

ap compared with intake

$\frac{0}{0}$
$\frac{0}{0}$
$\frac{0}{0}$
0

No disturbance of sediment

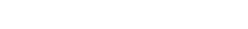

Faeces present in forest

Faeces present in water

$-2$

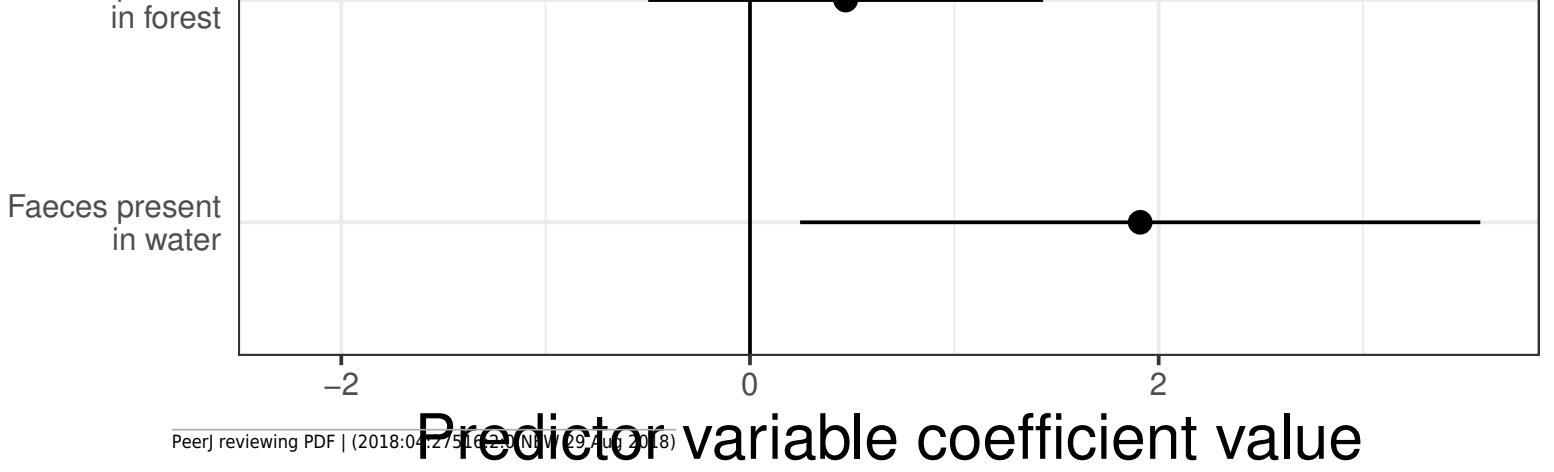


Figure 5 (on next page)

RCT difference-in-differences analysis matched on baseline $E$. coli contamination

This analysis includes only the subset of communities where the sampling location remained the same between baseline and end-line (communities $\mathrm{N}=47$ ). The model shows no effect of the intervention on microbial water quality (the error bars on the coefficient 'difference in difference in E. coli CFU concentration between 2010 and 2015 between treatment and control sites' overlaps zero). The coefficients and confidence intervals are presented in Table S5. 
Figure 6 (on next page)

RCT analysis for end-line data only from all communities for which we have end-line data (communities $\mathrm{N}=116$ ) controlling for predictors of $E$. coli contamination.

This shows no effect of the intervention on microbial water quality (the error bars on the coefficient 'End-line effect of being a treatment community' overlaps zero). The coefficients and confidence intervals are presented in Table S6. 
Log-transformed 2015

E. coli CFU concentration in control sites (20ml equivalent)

Tap compared with intake

Spring intake compared with stream intake

Endline effect of being a treatment community site

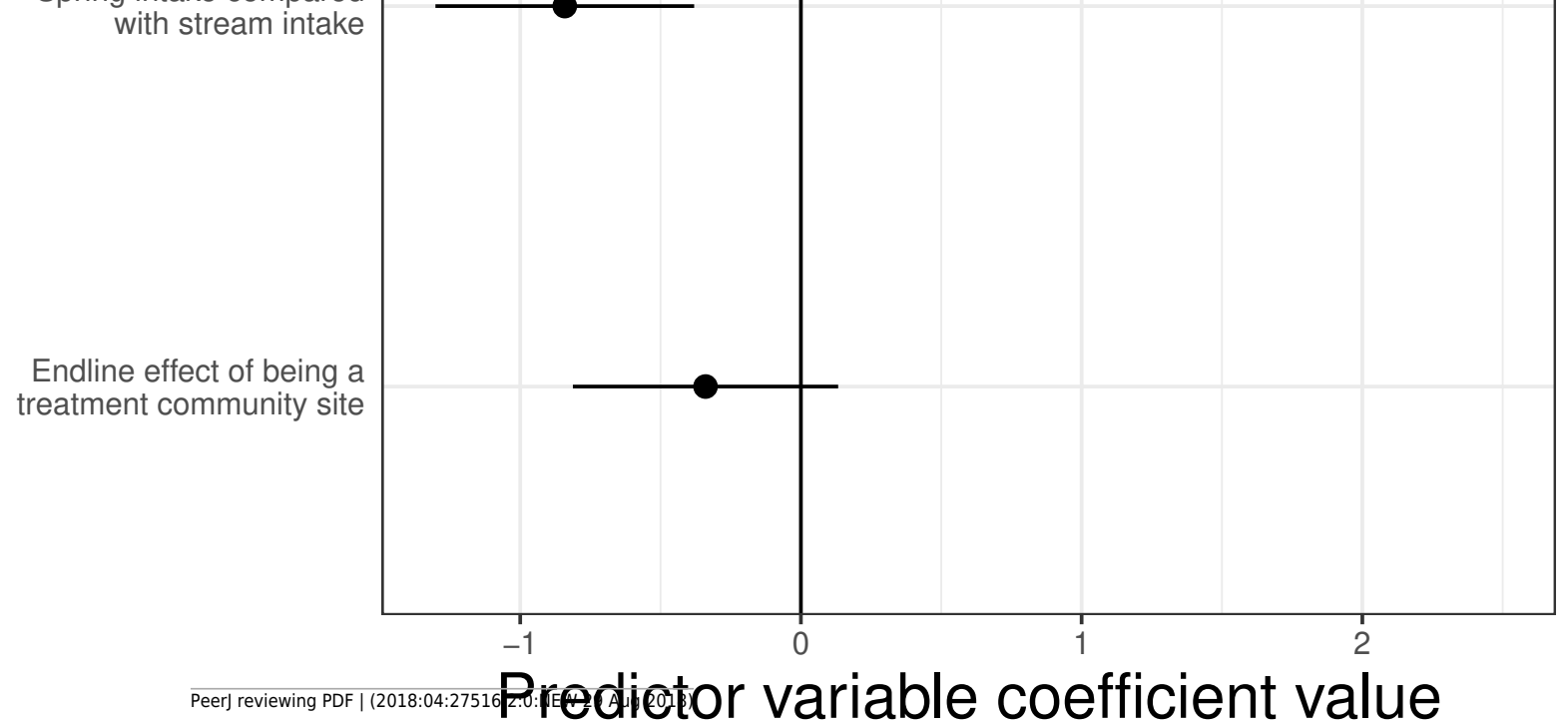


Figure 7 (on next page)

Box plots showing the difference between control and treatment communities in the proportion of eligible land enrolled in level 1 Watershared agreements.

The data is shown for all communities for which baseline water quality is available and the subset of communities for which we have a directly comparable end-line. 


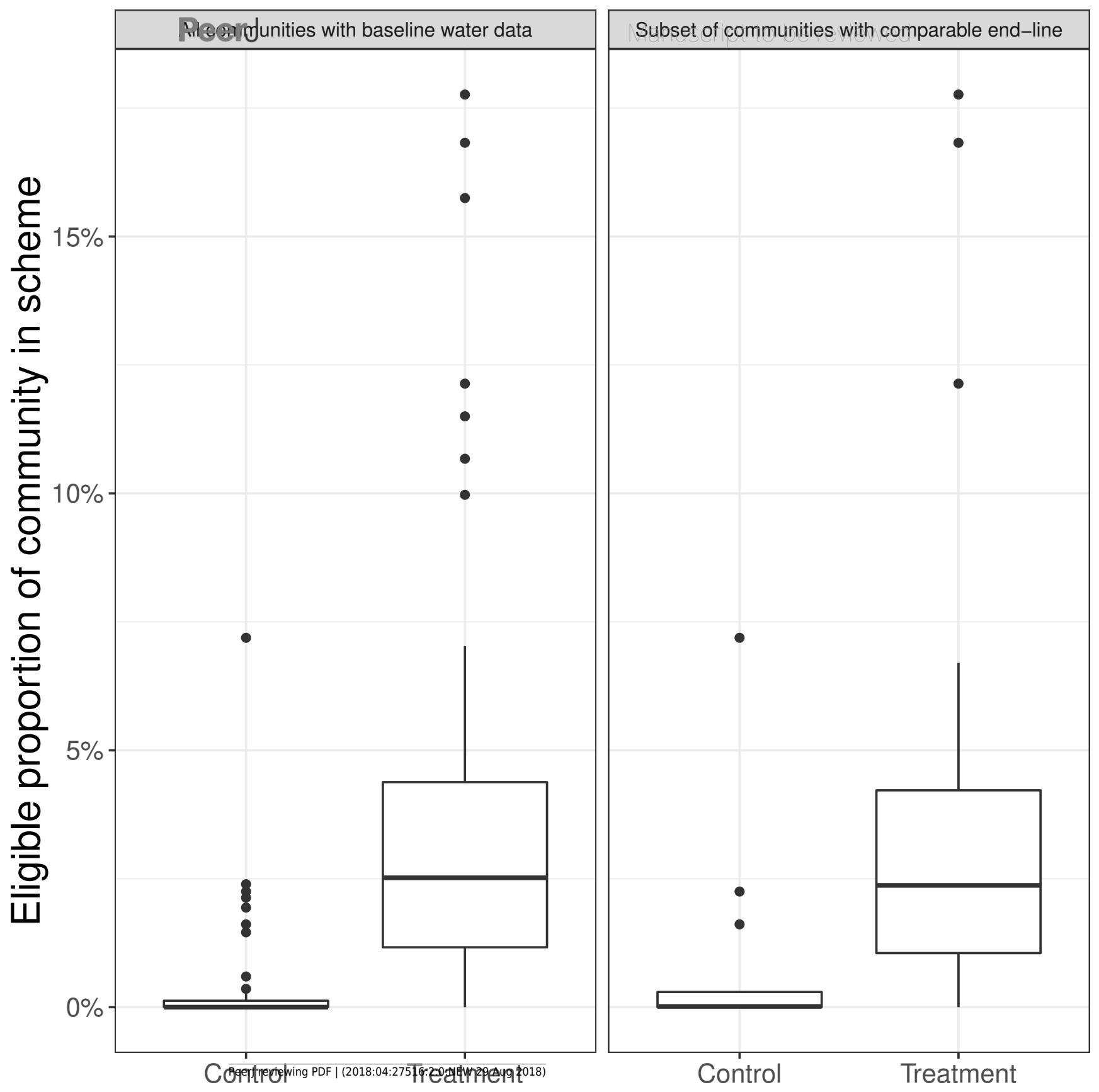




\section{Table $\mathbf{1}$ (on next page)}

Variables hypothesized to be important in predicting E. coli concentration in 2015.

Codes are used in subsequent model selection tables (Tables S4a and S4b). 


\begin{tabular}{|l|l|l|l|}
\hline Variable & Code & Classification & Base level \\
\hline Site type & ST & Intake; Tap & Intake \\
\hline Intake category & IC & Stream; Spring & Stream \\
\hline Sediment disturbance & SD & Undisturbed; Disturbed & Undisturbed \\
\hline Intake substrate & IS & Rock only; with sand; with mud & Rock only \\
\hline Cattle presence & C & Absent; Present & Absent \\
\hline Agriculture presence & A & Absent; Present & Absent \\
\hline Turbidity & Tu & Continuous; FAU/100 & - \\
\hline Temperature & T & Continuous & - \\
\hline Salinity & S & Continuous & - \\
\hline pH & pH & Continuous & - \\
\hline Cattle access & CA & Yes; No & Yes \\
\hline Faces presence & F & $\begin{array}{l}\text { Absent; Present in forest; Present in } \\
\text { water or on stream banks }\end{array}$ & Absent \\
\hline $\begin{array}{l}\text { Compliant level } \\
\text { Watershared area }\end{array}$ & ARA & $\begin{array}{l}\text { None; Intake entirely within conserved } \\
\text { area }\end{array}$ & None \\
\hline
\end{tabular}

1 


\section{Table 2 (on next page)}

Number (and proportion) of intakes visited in 2015 in compliant Watershared agreements and protected from cattle compared between treatment and control communities. 


\begin{tabular}{|l|l|l|}
\hline & $\begin{array}{l}\text { Treatment community } \\
\text { intake }\end{array}$ & $\begin{array}{l}\text { Control community } \\
\text { intake }\end{array}$ \\
\hline$N$ & 68 & 61 \\
\hline $\begin{array}{l}\text { Compliant level 1 Watershared } \\
\text { conservation agreement (\%) }\end{array}$ & $16(24 \%)$ & $0(0 \%)$ \\
\hline Sites with no cattle access (\%) & $40(59 \%)$ & $37(61 \%)$ \\
\hline
\end{tabular}

1 